\title{
Potential Role of Preoperative Conventional MRI Including Diffusion Measurements in Assessing Epidermal Growth Factor Receptor Gene Amplification Status in Patients with Glioblastoma
}

\author{
R.J. Young, A. Gupta, A.D. Shah, J.J. Graber, A.D. Schweitzer, A. Prager, W. Shi, Z. Zhang, J. Huse, and A.M.P. Omuro
}

\begin{abstract}
BACKGROUND AND PURPOSE: Epidermal growth factor receptor amplification is a common molecular event in glioblastomas. The purpose of this study was to examine the potential usefulness of morphologic and diffusion MR imaging signs in the prediction of epidermal growth factor receptor gene amplification status in patients with glioblastoma.

MATERIALS AND METHODS: We analyzed pretreatment MR imaging scans from 147 consecutive patients with newly diagnosed glioblastoma and correlated MR imaging features with tumor epidermal growth factor receptor amplification status. The following morphologic tumor MR imaging features were qualitatively assessed: 1) border sharpness, 2) cystic/necrotic change, 3) hemorrhage, 4) T2-isointense signal, 5) restricted water diffusion, 6) nodular enhancement, 7) subependymal enhancement, and 8) multifocal discontinuous enhancement. A total of 142 patients had DWI available for quantitative analysis. $A D C$ maps were calculated, and the $A D C_{\text {mean }}, A D C_{\text {min }}, A D C_{\text {max }}$, $A D C_{R O}$, and $A D C_{\text {ratio }}$ were measured.

RESULTS: Epidermal growth factor receptor amplification was present in 60 patients (40.8\%) and absent in 87 patients ( $59.2 \%)$. Restricted water diffusion correlated with epidermal growth factor receptor amplification $(P=.04)$, whereas the other 7 morphologic MR imaging signs did not $(P>$.12). Quantitative DWI analysis found that all ADC measurements correlated with epidermal growth factor receptor amplification, with the highest correlations found with $\mathrm{ADC}_{\mathrm{ROI}}(P=.0003)$ and $\mathrm{ADC}_{\text {mean }}(P=.0007)$.

CONCLUSIONS: Our results suggest a role for diffusion MR imaging in the determination of epidermal growth factor receptor amplification status in glioblastoma. Additional work is necessary to confirm these results and isolate new imaging biomarkers capable of noninvasively characterizing the molecular status of these tumors.
\end{abstract}

ABBREVIATIONS: EGFR $=$ epidermal growth factor receptor; GRE $=$ gradient recalled-echo

$\mathrm{T}$ he prognosis of patients with glioblastoma, the most common primary brain tumor, remains dismal, with a median overall survival duration of 16-17 months. ${ }^{1}$ Significant advances have recently been made toward a better understanding of the molecular mechanisms underlying gliomagenesis, however, with the ultimate goal of improving outcomes. Glioblastoma was the first human cancer sequenced by The Cancer Genome Atlas network effort, ${ }^{2}$ resulting in a comprehensive characterization of the mutational spectrum of this type of tumor. On the basis of integrated

Received December 31, 2012; accepted after revision March 12, 2013.

From the Departments of Radiology (R.J.Y., A.D. Shah, A.D. Schweitzer, A.P.), Neurology (J.J.G., A.M.P.O.), Epidemiology and Biostatistics (W.S., Z.Z.), and Pathology (J.H.) and Brain Tumor Center (R.J.Y., A.M.P.O.), Memorial Sloan-Kettering Cancer Center, New York, New York; and Department of Radiology (A.G.), Weill Cornell Medical College/New York Presbyterian Hospital, New York, New York.

R.J.Y. and A.G. co-drafted the original manuscript together and contributed equally as co-first authors. Z.Z. and W.S. performed statistical analysis.

Please address correspondence to Robert J. Young, MD, Department of Radiology, Memorial Sloan-Kettering Cancer Center, 1275 York Ave, MRI-1156, New York, NY 10065; e-mail: youngr@mskcc.org

http://dx.doi.org/10.3174/ajnr.A3604 genomic analysis, molecular classifications have been proposed with the intent of providing more uniform tumor subclasses from a biologic standpoint. ${ }^{3,4}$ Continued genomic sequencing efforts are expected to have expanding roles in the selection of patients for clinical trials and the development of more individualized and specific targeted therapies.

Activation of the epidermal growth factor receptor (EGFR) pathway is one of the most frequent molecular events in glioblastomas, with EGFR overexpression or amplification observed in up to $50 \%$ of patients. ${ }^{5-7}$ The EGFR gene is located on chromosome $7 \mathrm{p} 12$ and is more commonly amplified in primary glioblastoma than in secondary glioblastoma. ${ }^{8}$ Activation of EGFR pathways is associated with increased motility, adhesion, invasion, and proliferation of tumor cells, as well as inhibition of apoptosis and induction of angiogenesis. ${ }^{9,10}$ High-level EGFR amplification is a hallmark of the so-called Classical glioblastoma subtype, found in up to $97 \%$ of patients in that subgroup. ${ }^{3}$

DWI has correlated with cellular attenuation and gained increasing use in the evaluation of brain tumors, including glioblastoma. ${ }^{11-20}$ The role of DWI in the prediction of EGFR amplifica- 


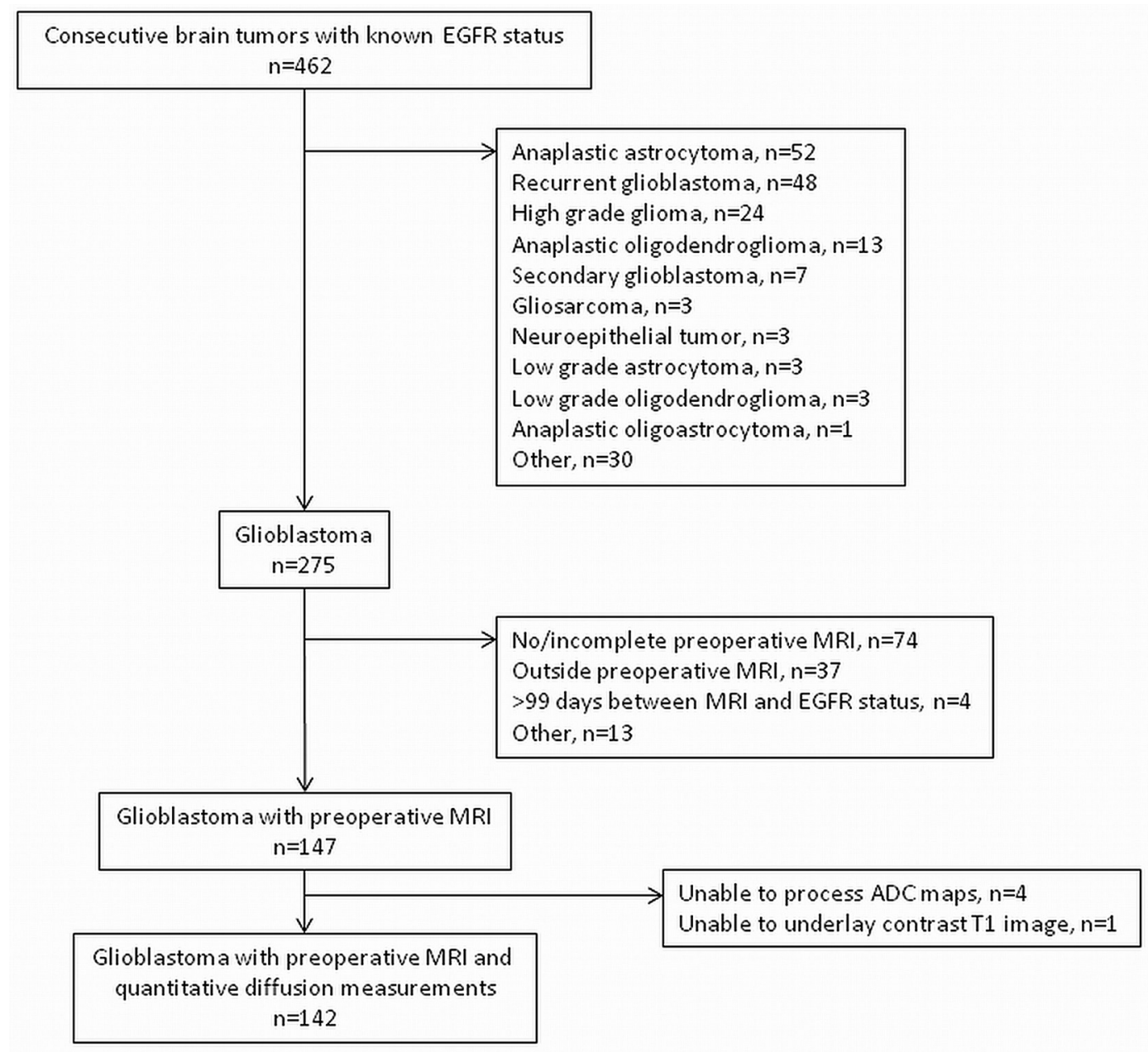

FIG 1. Main patient cohort.

tion status, however, has not been previously investigated. We hypothesized that the increased tumor cell proliferation and survival mediated by EGFR amplification will be measurable by DWI as restricted water diffusion. The purpose of this study was to investigate the potential role of morphologic and diffusion MR imaging features in the prediction of EGFR amplification status in patients newly diagnosed with glioblastoma.

\section{MATERIALS AND METHODS}

\section{Standard Protocol Approvals, Registrations, and Patient Consents}

This retrospective study was granted a Waiver of Informed Consent by the local institutional review board. The study was approved by the hospital privacy board and was compliant with Health Insurance Portability and Accountability Act regulations.

\section{Patients}

We retrospectively searched a hospital data base for patients newly diagnosed with glioblastoma with known EGFR amplification status treated between September 1, 2008, and October 31, 2011. As summarized in Fig 1, we determined the main patient cohort of 147 consecutive patients after applying the following inclusion criteria: 1) known EGFR amplification status; 2) pathologic diagnosis of glioblastoma according to revised World Health Organization criteria after biopsy, subtotal resection, or gross to-

2272 Young Dec 2013 www.ajnr.org

tal resection; and 3) preoperative conventional brain MR imaging. Charts were reviewed to determine overall survival.

\section{Conventional MR Imaging Parameters}

MR imaging was performed with 1.5T (Signa Excite, HDx; GE Healthcare, Milwaukee, Wisconsin) and 3T magnets (Discovery 750; GE Healthcare). We acquired all images by using 5-mm section thickness and no intersection gap. The standard preoperative imaging protocol consisted of sagittal and axial T1-weighted images; axial T2-weighted images; axial gradient recalled-echo (GRE) or SWI; axial DWI with ADC maps; and contrast coronal, sagittal, and axial T1-weighted images. DWI was performed with single-shot echo-planar imaging by use of acquisitions at b-value $=0 \mathrm{~s} / \mathrm{mm}^{2}$ and b-value $=1000 \mathrm{~s} / \mathrm{mm}^{2}$. Gadopentetate dimeglumine (Magnevist; Bayer HealthCare Pharmaceuticals, Wayne, New Jersey) was injected though a peripheral venous catheter (18-21 gauge) at doses standardized by patient body weight $(0.2 \mathrm{~mL} / \mathrm{kg}$ body weight, to a maximum of $20 \mathrm{~mL}$ ). The same dose of contrast was administered for both $1.5 \mathrm{~T}$ and $3 \mathrm{~T}$ scans.

\section{Morphologic MR Imaging Signs}

Two board-certified radiologists (one with 7 years of experience, and the other with 13 years of experience and holding a Certificate of Added Qualification in neuroradiology) independently analyzed the 
MR imaging scans while blinded to the EGFR amplification status. The readers scored 8 different MR imaging signs and resolved disagreements by consensus. Each conventional MR imaging was scored in a binary fashion according to the presence or absence of the following morphologic signs: 1) border sharpness, 2) cystic/necrotic change, 3) hemorrhage, 4) T2-isointense signal, 5) restricted water diffusion, 6) nodular enhancement, 7) subependymal enhancement, and 8) multifocal discontinuous enhancement. Border sharpness was visually determined by inspection of the enhancing margins of the tumor on contrast T1-weighted images. We evaluated the presence of hemorrhage by inspecting SWI $(n=74)$; GRE $(n=31)$; or, if neither available, by inspecting the b-value $=0$ DWI $(n=42)$. The hemorrhage-sensitive GRE and SWI sequences were being incorporated into our standard imaging protocols during the study period, with SWI acquired in all cases since early 2011. Restricted water diffusion was determined by assessment of hyperintense areas on $b$-value $=1000$ $\mathrm{s} / \mathrm{mm}^{2}$ DWI that were confirmed as hypointense on ADC images, for exclusion of studies where hemorrhage, T2 shinethrough effects, or artifacts might mimic restricted water diffusion. To replicate the usual clinical practice, we qualitatively reviewed all studies at a standard 5-panel PACS station (Centricity Radiology, GE Healthcare).

\section{Quantitative DWI Analysis}

The quantitative DWI analysis and ADC measurements were performed by a trained operator (with 6 months of experience) under the direct supervision of a board-certified radiologist with a Certificate of Added Qualification in neuroradiology (with 13 years of experience), who verified the ROIs in all patients. The quantitative analyses were performed while blinded to the patient EGFR amplification status and the recorded morphologic MR imaging signs (including visual assessments of restricted water diffusion). Each scan was transferred to an off-line commercially available workstation and processed by use of commercially available software (FuncTools 4.6 on Advantage Workstation; GE Healthcare) to calculate ADC images from the DWI. The contrast T1-weighted images were selected as the underlay for the ADC images, and the section containing the maximal contrast-enhancing portion of the tumor was chosen. An ROI was manually drawn around the entire contrast-enhancing tumor while deliberately excluding blood vessels and areas of cystic, necrotic, and hemorrhagic change that might affect ADC values. The ROI was then mapped to the corresponding $\mathrm{ADC}$ images, and measurements of $\mathrm{ADC}_{\text {mean }}, \mathrm{ADC}_{\text {min }}$, and $\mathrm{ADC}_{\text {max }}$ from that $\mathrm{ROI}$ were recorded. In addition, $\leq 4$ small circular ROIs $\left(50-75 \mathrm{~mm}^{2}\right)$ were manually placed over solid areas of the enhancing tumor that also displayed restricted water diffusion to select the maximal ADC hypointensity, and the minimal value was recorded as $\mathrm{ADC}_{\mathrm{ROI}}$. This is a standard technique that has been described as highly reliable and reproducible for ROI measurements. ${ }^{21,22}$ We also obtained $\mathrm{ADC}_{\mathrm{ra}^{-}}$ tios by dividing $\mathrm{ADC}_{\mathrm{ROI}}$ by $\mathrm{ADC}_{\text {normal }}$ placed in the normal contralateral brain. Quantitative DWI analyses were performed in 142 scans; 5 scans (all in patients without EGFR amplification) were discarded because of technical errors in measurement of ADC, though qualitative analyses were performed.

\section{EGFR Analysis}

EGFR amplification status was determined by interphase/nuclear fluorescence in situ hybridization techniques on paraffin sections.
Table 1: Characteristics of patients

\begin{tabular}{lc}
\hline & Total \\
\hline No. of patients & 147 \\
Median age, y (age range) & $65.1(13.8-83.4)$ \\
Sex (\%) & \\
$\quad$ Female & $66(44.9)$ \\
$\quad$ Male & $81(55.1)$ \\
Extent of subsequent surgery (\%) & \\
$\quad$ Biopsy & $19(12.9)$ \\
$\quad$ Subtotal resection & $84(57.1)$ \\
Gross total resection & $44(29.9)$ \\
\hline
\end{tabular}

\section{Table 2: Qualitative analysis of morphologic MR imaging signs} $(n=147)$

\begin{tabular}{|c|c|c|c|}
\hline \multirow[b]{2}{*}{ MR Imaging Sign } & \multicolumn{2}{|c|}{ EGFR Status* } & \multirow[b]{2}{*}{$P$ Value } \\
\hline & $\begin{array}{l}\text { Not Amplified } \\
\qquad(n=87)\end{array}$ & $\begin{array}{c}\text { Amplified } \\
(n=60)\end{array}$ & \\
\hline Sharp borders & & & .23 \\
\hline Absent & $45(52)$ & $37(62)$ & \\
\hline Present & $42(48)$ & $23(38)$ & \\
\hline Cystic and/or necrotic & & & .12 \\
\hline Absent & $2(2)$ & $5(8)$ & \\
\hline Present & $85(98)$ & $55(92)$ & \\
\hline T2 isointense & & & .38 \\
\hline Absent & $74(85)$ & $54(90)$ & \\
\hline Present & $13(15)$ & $6(10)$ & \\
\hline Diffusion restricted & & & .04 \\
\hline Absent & $68(79)$ & $38(63)$ & \\
\hline Present & $18(21)$ & $22(37)$ & \\
\hline Hemorrhage & & & .87 \\
\hline Absent & $36(41)$ & $24(40)$ & \\
\hline Present & $51(59)$ & $36(60)$ & \\
\hline Subependymal enhancement & & & .58 \\
\hline Absent & $74(85)$ & $49(82)$ & \\
\hline Present & $13(15)$ & $11(18)$ & \\
\hline Multifocal & & & .52 \\
\hline Absent & $58(67)$ & $43(72)$ & \\
\hline Present & $29(33)$ & $17(28)$ & \\
\hline
\end{tabular}

Per tissue sample, a total of 200 cells were analyzed and the results reported as the highest level of EGFR amplification in chromosome copies per cell. EGFR amplification was defined as $\geq 10$ copies per cell.

\section{Statistical Analysis}

Univariate analysis by the $\chi^{2}$ test or the Fisher exact test was performed to determine the relative usefulness of the morphologic MR imaging signs in the prediction of EGFR amplification status. The Wilcoxon rank sum test was performed to evaluate the quantitative ADC values. Significance was set to $P<.05$.

\section{RESULTS}

Demographic and patient information for the 147 main cohort participants are summarized in Table 1. A total of 60 patients (40.8\%) were determined to have high levels of EGFR amplification, whereas 87 (59.2\%) did not. The median interval between the MR imaging scan and surgery was 4 days (standard deviation, 10 days).

\section{Morphologic MR Imaging Signs}

The morphologic MR imaging results are summarized in Table 2. All patients in the cohort had preoperative morphologic MR imaging available for qualitative analysis. Restricted water diffusion 

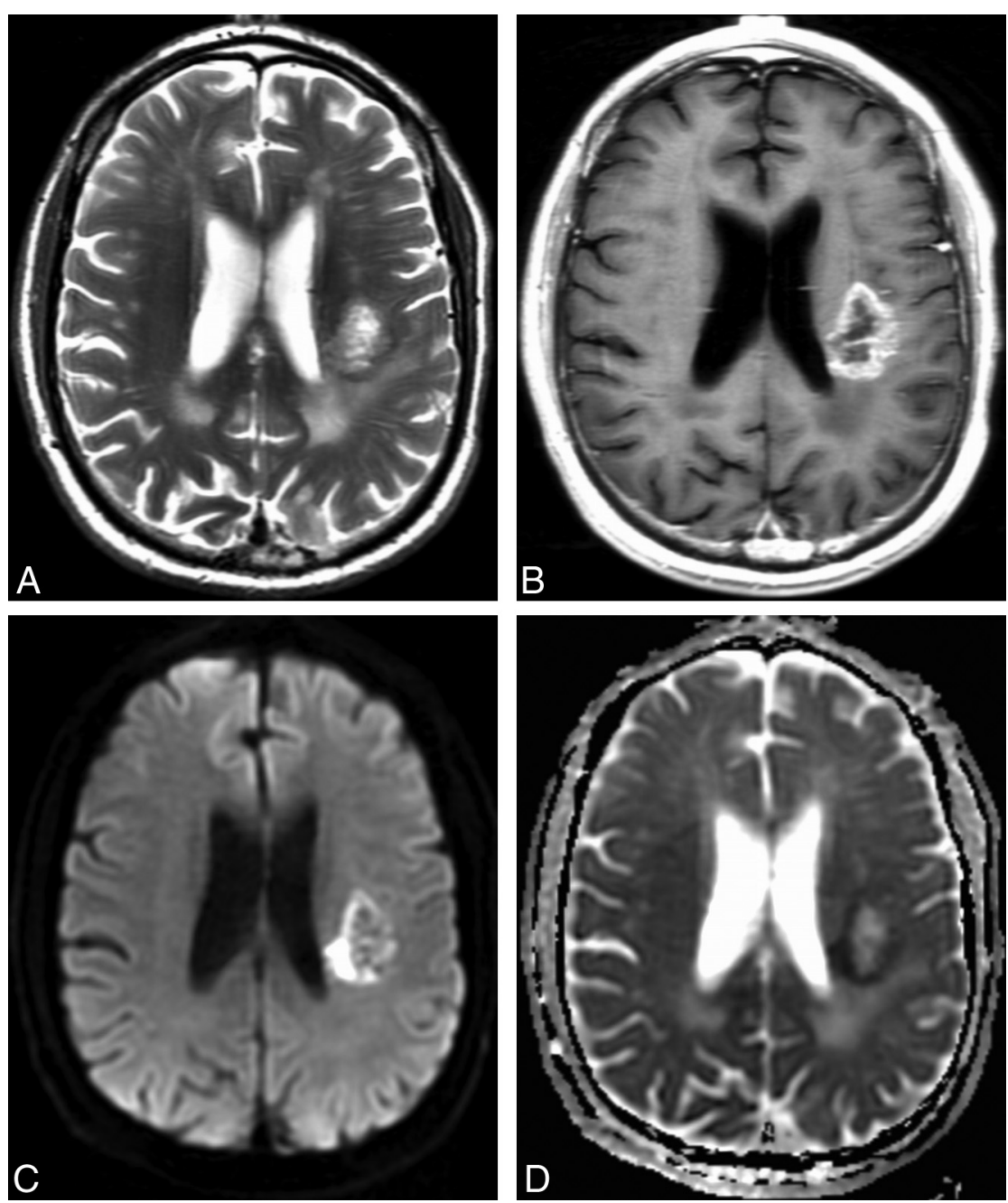

FIG 2. Representative example of restricted water diffusion in an EGFR-amplified tumor. Axial T2-weighted $(A)$ and contrast T1-weighted $(B)$ images show a heterogeneously enhancing glioblastoma in the left posterior corona radiata. DWI (C) shows hyperintense peripheral restricted water diffusion that is confirmed on the ADC image $(D)$ with a hypointense signal, and corresponds to the enhancing fraction seen in $(B)$. $A D C_{\text {mean }}$ measurement of the enhancing fraction was $0.13 \times$ $10^{-3} \mathrm{~mm}^{2 /} \mathrm{s}$. Fluorescence in situ hybridization analysis revealed high-level EGFR amplification with $98 \%$ of 200 analyzed cells showing $>20$ signals for EGFR.

occurred in 37\% of patients with EGFR amplification and in $21 \%$ of patients without EGFR amplification $(P=.04)$. A representative case is shown in Fig 2 . The related sensitivity $(36.7 \%$; 95\% CI, $24.9 \%-$ $50.2 \%)$ and specificity (79.1; 95\% CI, 68.7\%-86.8\%), however, were moderate with area under the curve for the receiver operating characteristic curve $=0.579$. The remaining 7 morphologic MR imaging signs were not significant $(P>.12)$.

\section{Quantitative DWI Analysis}

Lower ADC values were found in EGFR-amplified tumors with all metrics showing $P<.01$, as summarized in Table 3 . The highest correlations were found for $\mathrm{ADC}_{\mathrm{ROI}}(P=.0003)$ and $\mathrm{ADC}_{\text {mean }}$ $(P=.0007)$. The predictive power was moderate, with the receiver operating characteristic analysis showing a maximal area under the curve for $\mathrm{ADC}_{\mathrm{ROI}}=0.680$.

\section{DISCUSSION}

The use of MR imaging-based parameters for noninvasive tumor molecular characterization is an emerging field in neuroimaging. ${ }^{23-30}$ By providing information about the molecular status of tumors when tissue is not available for analysis, molecular characterization may have direct implications for management and potentially provide therapeutic value. Imaging parameters may also provide insights into the biologic behavior of tumors and information on hypoxia, cell attenuation, and angiogenesis, as related to different tumor molecular subtypes. In this study, we focused on EGFR amplification, one of the most common molecular alterations in glioblastomas and a hallmark of the classic glioblastoma subtype. Approximately $40 \%$ of our patients demonstrated EGFR amplification, which is in line with a previous study reporting EGFR amplification in up to $50 \%$ of patients with glioblastoma. ${ }^{31}$ We found that restricted water diffusion correlated with EGFR amplification as assessed by quantitative analysis at a dedicated postprocessing workstation ( $P=.01$ to .0003$)$, as well as qualitative visual analysis at a clinical PACS reading station $(P=.04)$. These data suggest a potential role for diffusion analysis in the prediction of EGFR amplification status in glioblastoma. Aside from restricted water diffusion, we did not find other commonly reported imaging characteristics to be useful in predicting EGFR amplification.

The quantitative ADC values correlated more highly $(P=.01$ to $P=.0003)$ than the qualitative visual inspection of DWI and ADC images $(P=.04)$. The ADC measurements confirmed that restricted water diffusion correlated with EGFR amplification. Selection of the single maximal abnormality $\left(\mathrm{ADC}_{\mathrm{ROI}}\right)$ after placement of multiple small ROIs outperformed a normalized ratio $\left(\mathrm{ADC}_{\text {ratio }}\right)$ and segmentation of the enhancing tumor $\left(\mathrm{ADC}_{\text {mean }}, \mathrm{ADC}_{\text {min }}\right.$, $\left.\mathrm{ADC}_{\text {max }}\right)$. We did not detect any significant correlations between the morphologic MR imaging tumor characteristics and EGFR amplification. Previous studies, ${ }^{23,32}$ which have used sophisticated texture analysis methods at dedicated postprocessing workstations, have been able to correlate some morphologic MR imaging metrics. For example, Aghi et $\mathrm{al}^{32}$ concluded that that the ratio of T2-bright volume to T1-enhancing volume and T1 and T2 border sharpness coefficients were useful predictors for EGFR amplification status. In a similar fashion, Diehn et $\mathrm{al}^{23}$ reported on the usefulness of a ratio of contrast-enhancing tumor to necrotic tumor in the prediction of EGFR overexpression. The purpose of our morphologic MR imaging analysis was to isolate imaging features that are commonly described in radiology reports for usual clinical practice after visual analysis at a PACS workstation without any additional postprocessing steps. 
Table 3: Quantitative analysis of ADC correlation with EGFR ( $n=142)$ EGFR Status*

\begin{tabular}{lccllr} 
& \multicolumn{2}{c}{} & & & \\
\cline { 2 - 3 } & Not Amplified $(\boldsymbol{n}=82)$ & Amplified $(\boldsymbol{n}=60)$ & & $\boldsymbol{P}$ Value & AUC \\
\hline $\mathrm{ADC}_{\text {mean }}$ & $1.27(0.90-1.97)$ & $1.15(0.11-1.70)$ & .0007 & 0.667 \\
$\mathrm{ADC} C_{\text {min }}$ & $0.90(0.16-8.38)$ & $0.83(0.51-1.23)$ & .01 & 0.624 \\
$\mathrm{ADC}_{\text {max }}$ & $2.11(1.22-3.28)$ & $1.77(0.86-3.01)$ & .005 & 0.639 \\
$\mathrm{ADC}_{\text {ROI }}$ & $1.06(0.56-1.59)$ & $0.93(0.67-1.30)$ & .0003 & 0.680 \\
$\mathrm{ADC}_{\text {ratio }}$ & $1.37(0.13-2.33)$ & $1.22(0.77-1.95)$ & .003 & 0.645 \\
\hline
\end{tabular}

Note:-AUC indicates area under the curve.

* Reported as median (range) $\times 10^{-3} \mathrm{~mm}^{2} / \mathrm{s}$ with $P$ values by the Wilcoxon rank sum test.

Increased EGFR amplification has been associated with increasing levels of tumor proliferation, angiogenesis, and invasiveness. ${ }^{5,33}$ The mechanisms for restricted water diffusion are complex, with increased cellularity such as in lymphoma suggested to be the most important factor. ${ }^{34}$ Restricted water diffusion has also been well correlated with ischemia and cytotoxic edema; it is unclear if restricted water diffusion occurs because of increases in tumor cellularity or ischemia, or both. ${ }^{15,35,36}$ Many tumors including glioblastoma overexpress hypoxia-inducible transcription factor-2 alpha, a powerful driver of oncogenesis that helps modulate the downstream EGFR-signaling pathway. ${ }^{36-38}$ The relationship between EGFR and tumor ischemia is further complicated by studies suggesting a protective effect of EGFR inhibition on hypoxic tumor cells that has limited the efficacy of the EGFR inhibitors in clinical trials. ${ }^{39,40}$ The patients in the current study all had untreated glioblastoma, which precludes treatment-related confounders such as radiation, antiangiogenic therapy, and EGFR inhibitor therapy on diffusion characteristics. Although this area requires further study, we suggest that tumor cellularity and ischemia probably both play a role in causing increased restricted water diffusion with EGFR amplification.

Several potential applications are available for predicting EGFR amplification status in patients with glioblastoma. The first relates to work from The Cancer Genome Atlas Research Network, ${ }^{3}$ which proposes the molecular classification of glioblastomas into Classical, Mesenchymal, Proneural, and Neural subtypes on the basis of gene expression aberrations of EGFR, NF1, and PDGFRA/IDH1. Of these, EGFR amplification was observed in $97 \%$ of the Classical subtype and less commonly in the other subtypes, ${ }^{3}$ indicating that the noninvasive imaging profiling of EGFR amplification may have a role in predicting the Classical vs other subtypes. Designating the Classical subtype is important for clinical decision-making, as this information may help predict patient prognosis and patterns of tumor progression, particularly when combined with imaging-based biomarkers. ${ }^{4,28}$ Second, despite the promising but tempered efficacy of early-generation EGFR tyrosine kinase inhibitors such as erlotinib, gefitinib, and vandetanib, ${ }^{41-45}$ it is possible that subsequent EGFR inhibitors will provide durable improvements in outcome. Recent comparisons to non-small-cell lung cancer have shown that efficacy correlates with higher EGFR receptor binding-site occupancies, ${ }^{25,46-49}$ suggesting avenues for development of future EGFR inhibitors to use in selected glioblastomas. Therefore, the importance of EGFR amplification status may grow with the development of newer treatments. Third, studies have suggested that serial imaging with $\mathrm{ADC}$ analysis and quantification may be useful to document response to treatment, ${ }^{50,51}$ though this has not been performed with EGFR inhibitor studies. Following EGFR amplification status during treatment with a targeted chemotherapeutic agent may provide insight into the efficacy of the treatment and subsequent treatment-induced changes in the tumor.

One potential limitation of our investigation is its retrospective nature. By examining preoperative conventional MR imaging scans in treatment-naïve primary glioblastomas, however, we present a homogeneous patient population from which correlations with EGFR amplification status are made. A second potential limitation was the ROI technique used to quantify the presence or absence of restricted water diffusion. Because our study was retrospective in that the exact sites of pathologic analysis were not recorded, it is possible that the measured levels of EGFR amplification did not directly reflect the maximal diffusion abnormalities measurements. Further study with locus-specific radiologic-histopathologic correlation would help clarify this relationship. The intratumoral cell-to-cell variability of EGFR expression has also been described as relatively low, ${ }^{31}$ suggesting that the observed correlations accurately reflect the relationship between EGFR expression and restricted water diffusion. Third, there was no consensus definition of EGFR amplification. ${ }^{31,52}$ We defined EGFR amplification as $\geq 10$ copies per cell after discussion with experienced neuro-oncologists, neuropathologists, neurosurgeons, and neuroradiologists at a National Cancer Institute-designated Comprehensive Cancer Center. This does not take into account the number of cells containing the gene amplification and may not be representative of the entire tumor; however, this relatively conservative interpretation is consistent with standard clinical and research practice at our institution and around the country.

\section{CONCLUSIONS}

Our study suggests possible usefulness for DWI to predict EGFR amplification status in patients with glioblastoma. EGFR status information may be useful in the prediction of Classical subtype glioblastomas. Imaging has potential value for patients in whom multiple genetic and molecular analyses may be difficult or infeasible, such as when tissue is not available for study. Further research with locus-specific histopathologic correlations and follow-up after patient treatment may help us to fully explore the prognostic value and underlying physiologic basis of restricted water diffusion in EGFR amplification.

\section{ACKNOWLEDGMENT}

We thank Ms. Judith A. Lampron for her expert editorial advice.

Disclosures: Robert Young—UNRELATED: Consultancy: ICON Medical Imaging, Comments: Blinded independent reviewer. Jerome Graber-UNRELATED: Payment for Lectures (including service on Speaker Bureaus): Speaker bureau for Biogen Idec; Other: Participation in market research studies for Olson Online Systems. Alisa Prager-UNRELATED: Grants/Grants Pending: MSKCC, NCI, Medical Student Summer Research Fellowship Program.* Antonio Omuro-UNRELATED: Consultancy: Roche, Novocure. *Money paid to institution.

AJNR Am J Neuroradiol 34:2271-77 Dec 2013 www.ajnr.org 


\section{REFERENCES}

1. Stupp R, Mason WP, van den Bent MJ, et al. Radiotherapy plus concomitant and adjuvant temozolomide for glioblastoma. $N$ Engl J Med 2005;352:987-96

2. Hu LS, Eschbacher JM, Heiserman JE, et al. Reevaluating the imaging definition of tumor progression: perfusion MRI quantifies recurrent glioblastoma tumor fraction, pseudoprogression, and radiation necrosis to predict survival. Neuro Oncol 2012;14:919-30

3. Verhaak RG, Hoadley KA, Purdom E, et al. Integrated genomic analysis identifies clinically relevant subtypes of glioblastoma characterized by abnormalities in PDGFRA, IDH1, EGFR, and NF1. Cancer Cell 2010;17:98-110

4. Phillips HS, Kharbanda S, Chen R, et al. Molecular subclasses of high-grade glioma predict prognosis, delineate a pattern of disease progression, and resemble stages in neurogenesis. Cancer Cell 2006;9:157-73

5. Lal A, Glazer CA, Martinson HM, et al. Mutant epidermal growth factor receptor up-regulates molecular effectors of tumor invasion. Cancer Res 2002;62:3335-39

6. Mazzoleni S, Politi LS, Pala M, et al. Epidermal growth factor receptor expression identifies functionally and molecularly distinct tumor-initiating cells in human glioblastoma multiforme and is required for gliomagenesis. Cancer Res 2010;70:7500-13

7. Schlegel J, Merdes A, Stumm G, et al. Amplification of the epidermal-growth-factor-receptor gene correlates with different growth behaviour in human glioblastoma. Int J Cancer 1994;56:72-77

8. Ohgaki $\mathrm{H}$, Kleihues $\mathrm{P}$. Genetic pathways to primary and secondary glioblastoma. Am J Pathol 2007;170:1445-53

9. Halatsch ME, Schmidt U, Behnke-Mursch J, et al. Epidermal growth factor receptor inhibition for the treatment of glioblastoma multiforme and other malignant brain tumours. Cancer Treat Rev 2006;32:74-89

10. Ramis G, Thomas-Moya E, Fernandez de Mattos S, et al. EGFR inhibition in glioma cells modulates Rho signaling to inhibit cell motility and invasion and cooperates with temozolomide to reduce cell growth. PLoS One 2012; 7:e38770

11. Barajas RF Jr, Rubenstein JL, Chang JS, et al. Diffusion-weighted MR imaging derived apparent diffusion coefficient is predictive of clinical outcome in primary central nervous system lymphoma. AJNR Am J Neuroradiol 2010;31:60-66

12. Bulakbasi N, Guvenc I, Onguru O, et al. The added value of the apparent diffusion coefficient calculation to magnetic resonance imaging in the differentiation and grading of malignant brain tumors. J Comp Assist Tomogr 2004;28:735-46

13. Calli $\mathrm{C}$, Kitis $\mathrm{O}$, Yunten $\mathrm{N}$, et al. Perfusion and diffusion MR imaging in enhancing malignant cerebral tumors. Eur J Radiol 2006;58: $394-403$

14. Castillo M, Smith JK, Kwock L, et al. Apparent diffusion coefficients in the evaluation of high-grade cerebral gliomas. AJNR Am J Neuroradiol 2001;22:60-64

15. Gupta A, Young RJ, Karimi S, et al. Isolated diffusion restriction precedes the development of enhancing tumor in a subset of patients with glioblastoma. AJNR Am J Neuroradiol 2011;32:1301-06

16. Mills SJ, Soh C, Rose CJ, et al. Candidate biomarkers of extravascular extracellular space: a direct comparison of apparent diffusion coefficient and dynamic contrast-enhanced MR imaging-derived measurement of the volume of the extravascular extracellular space in glioblastoma multiforme. AJNR Am J Neuroradiol 2010;31:549-53

17. Young RJ, Gupta A, Shah AD, et al. Potential utility of conventional MRI signs in diagnosing pseudoprogression in glioblastoma. $\mathrm{Neu}$ rology 2011;76:1918-24

18. Barajas RF Jr, Phillips JJ, Parvataneni R, et al. Regional variation in histopathologic features of tumor specimens from treatment-naive glioblastoma correlates with anatomic and physiologic MR imaging. Neuro Oncol 2012;14:942-54

19. Pope WB, Kim HJ, Huo J, et al. Recurrent glioblastoma multiforme: ADC histogram analysis predicts response to bevacizumab treatment. Radiology 2009;252:182-89
20. Lee EJ, terBrugge K, Mikulis D, et al. Diagnostic value of peritumoral minimum apparent diffusion coefficient for differentiation of glioblastoma multiforme from solitary metastatic lesions. AJR Am J Roentgenol 2011;196:71-76

21. Wetzel SG, Cha S, Johnson G, et al. Relative cerebral blood volume measurements in intracranial mass lesions: interobserver and intraobserver reproducibility study. Radiology 2002;224:797-803

22. Law $M$, Young $R, B a b b ~ J$, et al. Histogram analysis versus region of interest analysis of dynamic susceptibility contrast perfusion $\mathrm{MR}$ imaging data in the grading of cerebral gliomas. AJNR Am J Neuroradiol 2007;28:761-66

23. Diehn M, Nardini C, Wang DS, et al. Identification of noninvasive imaging surrogates for brain tumor gene-expression modules. Proc Natl Acad Sci U S A 2008;105:5213-18

24. Carrillo JA, Lai A, Nghiemphu PL, et al. Relationship between tumor enhancement, edema, IDH1 mutational status, MGMT promoter methylation, and survival in glioblastoma. AJNR Am J Neuroradiol 2012;33:1349-55

25. Bruzzone MG, Eoli M, Cuccarini V, et al. Genetic signature of adult gliomas and correlation with MRI features. Expert Rev Molecular Diagn 2009;9:709-20

26. Tykocinski ES, Grant RA, Kapoor GS, et al. Use of magnetic perfusion-weighted imaging to determine epidermal growth factor receptor variant III expression in glioblastoma. Neuro Oncol 2012; 14:613-23

27. Gupta A, Omuro AM, Shah AD, et al. Continuing the search for MR imaging biomarkers for MGMT promoter methylation status: conventional and perfusion MRI revisited. Neuroradiology 2012;54: 641-43

28. Jain R, Poisson L, Narang J, et al. Genomic mapping and survival prediction in glioblastoma: molecular subclassification strengthened by hemodynamic imaging biomarkers. Radiology 2013;267:212-20

29. Pope WB, Mirsadraei L, Lai A, et al. Differential gene expression in glioblastoma defined by ADC histogram analysis: relationship to extracellular matrix molecules and survival. AJNR Am J Neuroradiol 2012;33:1059-64

30. Jain R, Poisson L, Narang J, et al. Correlation of perfusion parameters with genes related to angiogenesis regulation in glioblastoma: a feasibility study. AJNR Am J Neuroradiol 2012;33:1343-48

31. Choi BD, Archer GE, Mitchell DA, et al. EGFRvIII-targeted vaccination therapy of malignant glioma. Brain Pathol 2009;19:713-23

32. Aghi M, Gaviani P, Henson JW, et al. Magnetic resonance imaging characteristics predict epidermal growth factor receptor amplification status in glioblastoma. Clin Cancer Res 2005;11:8600-05

33. Goldman CK, Kim J, Wong WL, et al. Epidermal growth factor stimulates vascular endothelial growth factor production by human malignant glioma cells: a model of glioblastoma multiforme pathophysiology. Mol Biol Cell 1993;4:121-33

34. Kono K, Inoue $\mathrm{Y}$, Nakayama $\mathrm{K}$, et al. The role of diffusion-weighted imaging in patients with brain tumors. AJNR Am J Neuroradiol 2001;22:1081-88

35. Schaefer PW, Grant PE, Gonzalez RG. Diffusion-weighted MR imaging of the brain. Radiology 2000;217:331-45

36. Rieger J, Bähr O, Müller K, et al. Bevacizumab-induced diffusionrestricted lesions in malignant glioma patients. J Neurooncol 2010;99:49-56

37. Wang X, Schneider A. HIF-2alpha-mediated activation of the epidermal growth factor receptor potentiates head and neck cancer cell migration in response to hypoxia. Carcinogenesis 2010;31:1202-10

38. Franovic A, Holterman CE, Payette J, et al. Human cancers converge at the HIF-2alpha oncogenic axis. Proc Natl Acad Sci U A 2009;106:21306-11

39. Ronellenfitsch MW, Brucker DP, Burger MC, et al. Antagonism of the mammalian target of rapamycin selectively mediates metabolic effects of epidermal growth factor receptor inhibition and protects human malignant glioma cells from hypoxia-induced cell death. Brain 2009;132:1509-22

40. Steinbach JP, Klumpp A, Wolburg H, et al. Inhibition of epider- 
mal growth factor receptor signaling protects human malignant glioma cells from hypoxia-induced cell death. Cancer Res 2004;64:1575-78

41. Kesavabhotla K, Schlaff CD, Shin B, et al. Phase I/II study of oral erlotinib for treatment of relapsed/refractory glioblastoma multiforme and anaplastic astrocytoma. $J$ Exp Ther Oncol 2012;10:71-81

42. Prados MD, Chang SM, Butowski N, et al. Phase II study of erlotinib plus temozolomide during and after radiation therapy in patients with newly diagnosed glioblastoma multiforme or gliosarcoma. J Clin Oncol 2009;27:579-84

43. Brandes AA, Franceschi E, Tosoni A, et al. Epidermal growth factor receptor inhibitors in neuro-oncology: hopes and disappointments. Clin Cancer Res 2008;14:957-60

44. Wachsberger PR, Lawrence YR, Liu Y, et al. Epidermal growth factor receptor expression modulates antitumor efficacy of vandetanib or cediranib combined with radiotherapy in human glioblastoma xenografts. Int J Radiat Oncol Biol Phys 2012;82:483-91

45. Kreisl TN, McNeill KA, Sul J, et al. A phase I/II trial of vandetanib for patients with recurrent malignant glioma. Neuro Oncol 2012;14: 1519-26

46. Barkovich KJ, Hariono S, Garske AL, et al. Kinetics of inhibitor cy- cling underlie therapeutic disparities between EGFR-driven lung and brain cancers. Cancer Discov 2012;2:450-57

47. Mellinghoff IK, Wang MY, Vivanco I, et al. Molecular determinants of the response of glioblastomas to EGFR kinase inhibitors. $N$ Engl J Med 2005;353:2012-24

48. Haas-Kogan DA, Prados MD, Tihan T, et al. Epidermal growth factor receptor, protein kinase $\mathrm{B} / \mathrm{Akt}$, and glioma response to erlotinib. J Natl Cancer Inst 2005;97:880-87

49. Park JH, Lemmon MA. Occupy EGFR. Cancer Discov 2012;2: 398-400

50. Hamstra DA, Galban CJ, Meyer CR, et al. Functional diffusion map as an early imaging biomarker for high-grade glioma: correlation with conventional radiologic response and overall survival. $J$ Clin Oncol 2008;26:3387-94

51. Moffat BA, Chenevert TL, Lawrence TS, et al. Functional diffusion map: A noninvasive MRI biomarker for early stratification of clinical brain tumor response. Proc Natl Acad Sci U S A 2005; 102:5524-29

52. El Naqa I, Grigsby P, Apte A, et al. Exploring feature-based approaches in PET images for predicting cancer treatment outcomes. Pattern Recognit 2009;42:1162-71 